\title{
Niños limpios y trabajadores. El teatro guiñol posrevolucionario en la construcción de la infancia mexicana/
}

\author{
Healthy and Working children. \\ The Postrevolutionary Teatro Guiñol \\ and the Construction of Mexican Childhood
}

\section{Susana Sosenski}

Universidad Nacional Autónoma de México, México D.F.

Este artículo examina obras del proyecto de teatro guiñol posrevolucionario mexicano y los discursos que éstas utilizaron para construir un nuevo tipo de ciudadanía y de infancia. A partir de dos discursos protagónicos, el trabajo y la higiene, se analiza el teatro guiñol como una forma de didactismo político, transmisión ideológica y medio de propaganda del régimen y se apuntan algunos posibles resultados en el propósito de convertir a los niños en un puente entre el Estado y las familias mexicanas.

PALABRAS ClaVE: Teatro guiñol; Infancia; Educación; México posrevolucionario.

This article explores some plays of the Mexican postrevolutionary puppet play project, and the discourses that such plays used to construct a new type of citizenship and childhood. Considering two main discourses, work and hygiene, the puppet theater is analyzed as a form of didactic politics, ideological transference, and as means of propaganda for the regime. It also points out some possible results in the government's intentions of transforming children into a bridge between the State and the Mexican families.

KEYwords: Puppets; Childhood; Education; Postrevolutionary Mexico.

1 Agradezco la cuidadosa lectura, las sugerencias y los comentarios a una versión preliminar de este texto que realizaron Beatriz Urías Horcasitas y María Rosa Gudiño. 
Una vez que terminó la fase armada de la Revolución Mexicana (1910-1920) la retórica estatal insistió en la creación de un hombre nuevo. En esta época, también llamada de la "reconstrucción nacional", se buscó conformar una sociedad de individuos homogeneizados por los mismos valores, creencias y hábitos que debían construirse desde pequeños. ${ }^{2}$ Entre 1920 y 1940 las políticas públicas para la infancia se centraron en higienizarla; enseñar a las madres estrategias para una sana alimentación; evitar el abandono infantil y el nacimiento de niños enfermos; desarrollar en ellos el gusto y las habilidades del trabajo manual, liberarlos de fanatismos religiosos y, en lo posible, controlar sus hábitos, formas de expresión, modales y patrones de consumo. El niño nuevo integraría a su experiencia de vida los valores nacionales que le permitirían convertirse en el ciudadano moderno que requería el país. El ideal de infancia mexicana y de sociedad revolucionaria se construyó de manera simultánea.

Para moldear la infancia se requirieron múltiples políticas y producciones culturales, herramientas de propaganda y de didactismo político. En este artículo destaco los contenidos ideológicos que se difundieron a través del "teatro guiñol" del Departamento de Bellas Artes, un proyecto creado en 1932 que se concentró en divulgar un amplio abanico de valores como la alfabetización, la importancia de la escuela, el laicismo, la defensa de la expropiación petrolera, el trabajo y la higiene. Un estudio pionero sobre el teatro guiñol y la recepción infantil a los discursos de los títeres es el de Elena Jackson quien, de manera lúcida y a partir del análisis de archivos institucionales, así como de dibujos infantiles, trata una cuestión tortuosa en el ámbito de la historia cultural y la historia de la infancia: la recepción. ${ }^{3}$ Sin embargo, el tema del teatro guiñol no está agotado todavía y queda mucho por explorar. En este artículo me concentro en el análisis de los discursos de las obras de teatro alrededor de dos valores esenciales en lo que se consideraba la construcción del niño y del ciudadano revolucionario mexicano: el trabajo y la salud. Para ello me enfoco y rescato fuentes poco trabajadas hasta el momento: los guiones que quedaron hasta nuestros días de las obras de teatro guiñol para niños del Departamento de Bellas Artes.

Este proyecto puso "especial cuidado en los programas dirigidos a la niñez, considerando que en ella estaba el germen del futuro México", ${ }_{4}^{4}$ pero los adultos se convirtieron también en un destinatario central. Los titirite-

2 Knight, 1994, p. 395. Urías Horcasitas, 2007, p. 61. Hunt, 1984, p. 56.

3 Jackson, 2011.

4 Aréchiga, 2007, pp. 75-76. 
ros visitaron hospitales, plazas públicas, penitenciarías colonias populares, el pabellón infantil del Manicomio de La Castañeda, campos militares, fábricas, talleres, cárceles, ejidos, casas cuna, reformatorios y hospicios. Los domingos presentaron exhibiciones para el público general en la Alameda Central, apoyaron las misiones y brigadas culturales, las campañas de alfabetización para comunidades agrarias, visitaron sindicatos obreros y agrupaciones campesinas. ${ }^{5}$

\section{El surgimiento del teatro guiñol pedagógico}

Uno de los grandes cambios que provocó la Revolución Mexicana se dio en el ámbito educativo. En 1921, José Vasconcelos creó la Secretaría de Educación Pública (SEP) e inició un amplio proyecto para todo el país. La escolarización de la población infantil fue en ascenso. La pedagogía de la acción de John Dewey y la educación socialista, tomada del ejemplo ruso, guiaron la ecléctica práctica educativa mexicana entre 1920 y 1940. Los principios de "aprender haciendo" la enseñanza a partir de las experiencias cotidianas de los niños, así como el fomento de valores como el corporativismo, la cooperación, la solidaridad y el amor del trabajo, llegaron a las escuelas y a las comunidades de las áreas más remotas de la República.

El interés de la SEP por emplear a los títeres como vehículos didácticos para alfabetizar, adoctrinar y dar publicidad al régimen se nutrió de experiencias previas. ${ }^{6}$ El proyecto de teatro guiñol de Bellas Artes que veremos aquí fue apoyado por el secretario de educación, Narciso Bassols, convencido marxista, defensor del laicismo, de la enseñanza de educación sexual, y comprometido con la causa de los exiliados republicanos españo-

5 Es importante señalar que las fuentes no nos permitieron rastrear por ahora cuáles eran las obras que se representaban en la Ciudad de México y cuales en las comunidades rurales, este es un tema pendiente para futuras investigaciones que busquen las implicaciones posibles de una obra en cada uno de esos ámbitos.

6 Cabe mencionar que el uso del teatro como adoctrinador, formador de valores o difusor de ideas no era nuevo; desde la época novohispana, por ejemplo, se había utilizado como un recurso efectivo para la evangelización. Véase Horcasitas, 2004. Miguel Hidalgo representó el Tartufo de Moliere para difundir sus ideas religiosas y José Joaquín Fernández de Lizardi para promover ideas independentistas. Ortiz, 2005, p. 256. La familia Rosete Aranda, desde 1835, creó una de las compañías más grandes de marionetas que habían existido en México, pero no tenía un objetivo didáctico. Bernardo Ortiz de Montellano en 1929 estableció en la Casa del Estudiante Indígena un teatro itinerante que luego recorrió las zonas rurales del país. Giménez Cacho, 2008, p. 5. En 1951 surgió el proyecto del teatro guiñol Petul en Chiapas, organizado por el Instituto Nacional Indigenista para la difusión de las campañas de salud, alfabetización y castellanización. Lewis, 2008. 
les en México. Carlos Chávez, titular del Departamento de Bellas Artes, se sumó al proyecto, así como un grupo de destacados hombres y mujeres del mundo de las artes y la cultura que habían tenido estrecho contacto con la vida artística y cultural europea: literatos, pintores, escultores, dramaturgos y músicos, entre los cuales se encontraban militantes del Partido Comunista Mexicano y la antifascista Liga de Escritores y Artistas Revolucionarios (LEAR). ${ }^{7}$

Los principales artífices de este esfuerzo fueron el escultor Germán Cueto, el pintor Ramón Alva de la Canal, el dramaturgo Roberto Lago, el pintor y tallador Enrique Assad y la escritora Graciela Amador (primera esposa del muralista David Alfaro Siqueiros). La destacada pintora rusa Angelina Beloff (quien fuera esposa de Diego Rivera) se encargaba de pintar la escenografía; Dolores Cueto elaboraba los muñecos; Julio Castellanos diseñaba los vestuarios; Silvestre Revueltas componía música para las obras mientras el escritor estridentista mexicano, Germán List Arzubide, cercano a las ideas socialistas del régimen de Cárdenas, colaborador de Bassols y encargado de vigilar "el cumplimiento de la ley contra las escuelas que daban educación religiosa" ${ }^{8}$ destinaba parte de su producción intelectual a la escritura de obras de teatro infantil.

Así, estos artistas e "intelectuales pedagogos" formaron parte de un amplio proyecto estatal para educar y concienciar al futuro ciudadano a través de producciones culturales en un contexto en el que la educación y el arte se erigieron no sólo como un binomio sino también como la panacea para formar política y socialmente a la población.

Es historia conocida ${ }^{10}$ que a fines de 1932 los grupos de teatro guiñol presentaron su proyecto ante Bassols y Chávez en un bodegón de la casa de Germán Cueto. El 22 de junio de 1933 la SEP llevó a cabo la primera función pública de prueba en el Teatro Orientación, en la Ciudad de México. Los grupos que se presentaron fueron el Grupo A, Rin Rin, de Cueto, y el Grupo B, Comino, dirigido por Leopoldo Méndez, que debían visitar dos o tres escuelas por día con representaciones de treinta minutos. El éxito obtenido y la necesidad de cubrir un amplio número de escuelas, hicieron que en 1934 se aprobara un presupuesto para un tercero, el Grupo C, Periquillo, dirigido por Graciela Amador y Roberto Lago.

7 Ortiz, 2005, p. 205.

8 Wilkie y Monzón Wilkie, 2001, p. 253.

9 Palacios, 1999.

10 Giménez Cacho, 2008. 
Aunque se contó con el financiamiento de la SEP, los titiriteros debieron enfrentarse a las trabas burocráticas que muchas veces dificultaban la fluidez del proyecto: se quejaban de que el jefe no los recibía, de trabajar mañana y tarde, e incluso los domingos, "en pleno aguacero", de no tener vacaciones y de que no se considerara su esfuerzo. ${ }^{11}$ Además faltaban radiolas, fonógrafos o discos para los bailables de las obras; $;{ }^{12}$ no había camiones que llevaran a los titiriteros y sus muñecos; ${ }^{13}$ en abril de 1935 un grupo tuvo que suspender sus funciones por la falta de doce tornillos para armar el tinglado $;{ }^{14}$ en ocasiones no se proporcionaban las direcciones precisas y los grupos no lograban llegar a las escuelas. ${ }^{15}$ Los establecimientos educativos no recibían a los titiriteros por diversos motivos: se había prolongado la asamblea de maestros, ${ }^{16}$ las alumnas estaban ensayando para el festival del Día de la Madre o los directores pretextaban que era demasiado tarde. ${ }^{17}$ Los autos eran alquilados y a veces bastante inseguros. En cierta ocasión, el dueño de una de las camionetas indicó, en un estilo muy nacional, que su vehículo "en realidad no está en buenas condiciones pero desde luego no piensa que corra peligro la vida de los ocupantes" ${ }^{18}$ En opinión de Roberto Lago si el proyecto guiñol tenía éxito era más por el entusiasmo de los titiriteros que por el interés de la SEP, que les había negado los recursos económicos y morales necesarios para desarrollarse con amplitud.

En poco tiempo los titiriteros lograron ser considerados como educadores y de tal forma fueron contratados por la SEP como "empleados de carácter docente". Graciela Amador y Ramón Alva de la Canal fueron comisionados en la Escuela Normal Superior para dar cursos a los maestros sobre técnica de teatro guiñol. Roberto Lago se autodefinió como un

11 Archivo Histórico de la Secretaría de Educación Pública (AHSEP), Bellas Artes, Teatro, 73, 22, "Respuesta de Dolores Alva de la Canal al oficio 13259", México, 24 de agosto de 1935, f. 70.

12 Ibidem, 73, 22, "Carta de Roberto Lago al jefe de la Sección de Teatro", México, 7 de octubre de 1935, f. 119.

13 Ibidem, 74, 4937, "Que se sirva solicitar de la superioridad se resuelvan las irregularidades que se citan", México, 1 de febrero de 1935, f. 9.

14 Ibidem, "Carta de Roberto Lago al jefe de la Sección de Teatro", México, 18 de abril de 1935, f. 146.

15 Ibidem, "Memorándum al jefe de Departamento de Bellas Artes", México, 28 de febrero de 1935 , f. 40.

16 Ibidem, "Carta de los directores de la XXV-9 y XXXV-12", México, 13 de marzo de 1935, f. 43 .

17 Ibidem, "Carta de Dolores Alva al encargado de la mesa del jefe de la Sección", México, 13 de mayo de 1935, f. 48.

18 Ibidem, "Carta al Sr. Roberto Lago", México, 2 de noviembre de 1936, f. 128. 
"titiritero pedagógico" señalando que "divertir instruyendo o instruir divirtiendo nos pareció la aspiración más alta que podía alcanzar la pedagogía moderna". ${ }^{19}$ Germán List Arzubide sintetizaba esta idea con la frase: "el teatro es, siempre, una escuela".

En un primer momento el proyecto se enfocó a los jardines de niños de los barrios obreros, y a la ciudad de México, pero poco a poco fue desplazándose a las escuelas primarias, a las zonas rurales y a otros estados de la República, en donde ya existían experimentos teatrales, como el "teatro campesino" institucionalizado por la SEP en el campo. ${ }^{20}$ Las escuelas que se visitaban debían estar cerca de las carreteras ya que el material de teatro guiñol no se podía llevar caminando sino que requería automóviles. ${ }^{21}$ Como los tres grupos no bastaban para cubrir la enorme demanda en el país y se pretendía que su esencia llegara al máximo de población posible, la SEP encargó al literato estridentista Arqueles Vela un manual para repartir en las escuelas de la República Mexicana. En éste se promovía que los maestros y los alumnos elaboraran sus propios títeres y escenarios de manera "económica, sencilla y cómoda", es decir, que se transformaran en una suerte de titiriteros. Revistas como El Maestro Rural, dirigida a los campesinos y a los docentes, publicaron también varias sugerencias para confeccionar muñecos y escenarios. ${ }^{22}$

La idea de la SEP fue que no hubiera "escuelita rural, por pobre que sea, que no tenga este medio de brindar satisfacciones estéticas a los niños campesinos". ${ }^{23}$ Pronto circularon noticias sobre las "hermosas y útiles labores" que realizaban los maestros y maestras de las escuelas primarias construyendo teatros de títeres. Dichas estrategias permitieron que "el teatro y el mensaje político educativo que venía implícito en estas propuestas llegaran a un número considerable de la población, particularmente en el amplio segmento de las clases populares, en escuelas, ejidos, barrios populares, municipios". ${ }^{24}$

19 AHSEP, Bellas Artes, Teatro, 75, 1, "Informe sobre las labores del Departamento de Teatro", México, s/f, fs. 15 y 16. Ortiz, Teatro, 2005, p. 262.

20 Palacios, 1999, p. 77.

21 AHSEP, Bellas Artes, Teatro, 73, 22, "Relación de escuelas del estado de Morelos", México, 3 de octubre de 1935, f. 113.

22 "Cartas a los maestros rurales. Cómo armar un teatro guiñol", El maestro rural, 5, México, 1 de marzo de 1936, p. 23.

23 "La construcción del teatro infantil y de títeres", El maestro rural, 12, México, 15 de junio de 1934 , p. 31.

24 Ortiz, 2005, pp. 260-261. 


\section{Educación y propaganda. Usos del teatro guiñol}

El niño, considerado como "un agente de transformación social y como elemento real y efectivo de la comunidad en la que actúa[ba]", debía formarse en "hábitos que lo [prepararan] para la sociedad socialista". ${ }^{25}$ En épocas revolucionarias el niño, en abstracto, aparece como agente social, como el autor del futuro que debe ser liberado del peso del pasado y moldeado con los ideales de la Revolución, porque es, en suma, el constructor del futuro revolucionario. ${ }^{26}$ En la concepción nacionalista de la época los niños mexicanos no nacían revolucionarios, se hacían.

El teatro guiñol posrevolucionario se convirtió en un puente ideológico entre los gobiernos en turno y la niñez mexicana, en una forma oficial de trascender los muros escolares y penetrar en los hogares. El médico Alfonso Pruneda opinaba que "el niño es el vínculo entre las instituciones sociales. Es un vector en las enseñanzas y prácticas que adquiere y que sólo puede modificar en el ámbito doméstico". ${ }^{27}$ Los niños escolarizados eran mediadores entre el Estado y las familias populares mexicanas, por eso el teatro guiñol apareció como una atractiva estrategia para tender redes entre estos círculos. En suma, el gobierno impulsó el teatro infantil, lo utilizó como propaganda ideológica y reconoció su importante función como vehículo didáctico.

No sólo el teatro guiñol sino el arte teatral en general, “desempeñó un papel muy relevante en la educación nacional, como parte de una práctica social y discursiva del proceso revolucionario" ${ }^{28}$ En el contexto de un arte popular "al servicio de los trabajadores" que debía ser "esencialmente un arma de lucha en los conflictos sociales" varias obras de guiñol tuvieron una tendencia militante, es decir, "integraron aspectos ideológicos con la propuesta estética". ${ }^{29}$ Algunos libretos eran adaptaciones de textos de Tolstoi, los hermanos Grimm, o Miguel de Cervantes, otros eran producciones mexicanas que tenían como objetivo instruir, atacar las relaciones sociales y los modos de producción capitalistas, infundir amor por el trabajo, convencer de la defensa de los recursos naturales, promover la alfabetización y divulgar campañas por la salud de la población.

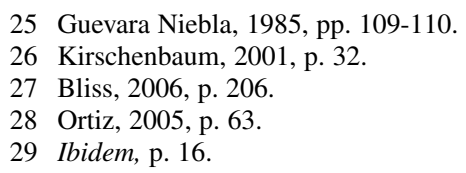


Las finalidades oficiales del teatro guiñol fueron: "educar cultural y políticamente al niño, dentro del criterio histórico materialista", contribuir a su formación moral, "liberarlo de todos los prejuicios raciales, religiosos o sexuales"; fomentar en él "la conquista y dominio de las fuerzas naturales como único objetivo de la vida social"; formarle "el concepto de que el trabajo es el único medio de conquistar el bienestar colectivo"; "desarrollar sus sentidos estéticos"; hacer desaparecer de su mente del "la existencia de seres fabulosos, como hadas, gnomos, duendes"; promover la higiene, "educarlo, en general, por medio del teatro". ${ }^{30}$

La función ideologizadora del teatro fue tan intensa y evidente que la SEP consideraba "necesario contar entre las obras esencialmente tendenciosas, algunas que ayuden a la ligereza del espectáculo y contribuyan a interesar a los niños". ${ }^{31}$ Una Comisión de repertorio se encargó de leer, revisar, seleccionar, corregir, reescribir o pedir cambios a las obras que se presentaban. ${ }^{32}$ Para 1935 se señaló que los programas debían contar con "una obra de fondo ideológico", "una obra cómica de carácter recreativo" y "una obra rítmica (ballet)". ${ }^{33}$ La SEP buscaba:

escritores jóvenes de filiación definitivamente socialista para escribir las obras que formarían el repertorio de teatro guiñol a fin de que escriban obras en las que se haga ver a los niños en general, y a los que pertenecen a las masas trabajadoras muy especialmente, los beneficios de una nueva organización social más humana y justa, mostrándoles en dónde está su enemigo de clase y cómo deben defenderse de la explotación, y también, cómo apartarse de toda idea individualista prefiriendo el bien colectivo. ${ }^{34}$

Se insistía en que el objetivo era "contribuir a la educación social del niño dándole las bases de una nueva moral, destruyendo en ellos supersticiones que la ignorancia ha venido sembrando". ${ }^{35}$ Juan Bustillo Oro, uno de los miembros de la citada Comisión, señalaba que

para una educación revolucionaria que aspira a ir cimentando en la conciencia del país una nueva moral social que permita los forzosos cambios económicos que mar-

30 María y Campos, 1941, p. 23.

31 AHSEP, Bellas Artes, Teatro, 73, 11, "Carta al Jefe del Departamento de Bellas Artes", México, 6 de marzo de 1934, fs. 46-47.

32 Ibidem, 73, 11, "Carta del jefe de la Sección de Teatro", México, 30 de enero de 1934, f. 17.

33 Ibidem, 74, 4937, "Funcionamiento de los grupos de teatro guiñol", México, 16 de abril de 1935 , f. 140 .

34 Ibidem, 74, 4937, "Departamento de Bellas Artes de la Secretaría de Educación Pública", México, s/f, f. 19. f. 387 .

35 Ibidem, 71, 33-34, "Proyecto de contestación al oficio girado por la profesora", México, s/f, 
ca la Revolución y que a ella misma obligan, el teatro (infantil o para adultos) no puede ser visto como un mero desahogo artístico. [...] Apoderarse del niño, hacerlo para la Revolución, he aquí la tarea de la Educación impartida por el Estado en la que el teatro debe tomar su lugar dignamente, y con el espíritu de sacrificio que nuestra época de transición exige. ${ }^{36}$

Este teatro al servicio de la "pedagogía revolucionaria" basó sus antecedentes en la experiencia rusa. Germán List Arzubide, por ejemplo, había visitado el teatro de los niños en Leningrado, inaugurado con la Revolución de Octubre y considerado como "una conquista de la revolución". A Angelina Beloff, el Departamento de Bellas Artes, en 1932, le había encargado traducir al castellano diversos folletos rusos sobre teatro guiñol. ${ }^{37}$ Los soviéticos tenían una sección pedagógica que observaba qué pasaba con los menores a medida que la obra avanzaba y aplicaban tests donde los niños debían escribir o dibujar algo para un periódico mural en el que los docentes analizaban las reacciones. ${ }^{38}$ Tomando este caso como ejemplo, en México la SEP solicitó que los directores de los jardines de niños enviaran dibujos de los alumnos para analizar la recepción de las obras.

En tanto hubo una intención explícita e insistente por ideologizar al niño y al espectador en general, no es fortuito que para ello se eligieran dos grandes temas y derechos sociales consignados en la Constitución de Querétaro de 1917 y que habían sido producto directo de la gesta revolucionaria: la higiene y el trabajo. Las obras de guiñol subrayaron que los niños mexicanos debían prepararse desde muy pequeños para la lucha por los derechos y la justicia colectivos, por los valores de la limpieza, la higiene, la eficiencia y la productividad. La sociedad en miniatura que se recreaba en el escenario defendía el valor del trabajo, criticaba a los "Enemigos de la Revolución": la burguesía, los patrones explotadores, los microbios y las bacterias. Por primera vez los muñecos guiñol formaban parte del movimiento social de concientización y se convertían en portavoces de la retórica revolucionaria.

\section{Los títeres enseñan a trabajar}

El cénit del teatro guiñol mexicano coincidió con la efervescencia de la escuela socialista instaurada por el régimen de Lázaro Cárdenas, cuyos

36 Bustillo Oro, p. 37.

37 Beloff, 1945, pp. 174-175.

38 Amador, 1936, pp. IV-VI. 
principios educativos residían en dirigirse "hacia las clases campesinas y obreras", vincularse "con los problemas del medio, las necesidades y aspiraciones de las agrupaciones proletarias" y crear "trabajadores manuales e intelectuales que, con conciencia de clase, puedan convertirse en eficientes y honestos directores de sus propios fines". ${ }^{39}$ Esta educación "propugnaba las formas colectivas de aprender la conducta productivista y nacionalista moderna: cooperativas productivas y de consumo, equipos deportivos, desempeño cultural, campañas antialcohólicas y sanitarias". ${ }^{40}$ La educación socialista fomentó el trabajo, exigió que los alumnos realizaran labores que les formaran hábitos laboriosos, que los identificaran con la clase productora y lo hicieran colectivamente ${ }^{41} \mathrm{El}$ trabajo se convirtió en el centro de la formación de la infancia. México requería ciudadanos trabajadores para entrar de lleno en la senda de la tan ansiada industrialización y muchos programas oficiales se enfocaron a difundir hábitos de trabajo entre la infancia pobre mexicana. Un complejo entramado en el que operaba la escuela, las casas correccionales, los talleres artesanales y la laxa aplicación de las leyes de protección a la infancia, pretendieron que los niños se integraran al mercado laboral lo más temprano posible..$^{42}$

En tanto la escuela socialista debía ser "combativa y crítica de todos los medios de esclavitud material y espiritual que degeneran y aniquilan la dignidad humana", ${ }^{43}$ en las obras de Germán List abundaron las críticas a las arbitrariedades del sistema capitalista. En Comino vence al diablo, un patrón que explotaba a su empleado, El Negrito, la representación racial de la explotación, exigía: "trabaja Negrito, trabaja que así es como se hace uno rico". Consciente de su situación laboral El Negrito respondía: "Así es como se hace usted rico, pero yo no". ${ }^{44} \mathrm{El}$ empleador abusivo, disfrazado de Diablo para imponer miedo en sus trabajadores, no tenía mucho éxito ante títeres que simbolizan a una infancia unida en la lucha contra de las injusticias sociales. El títere Comino y su amigo El Negrito se organizaban para golpearlo con la avenencia de los niños del público: "¿verdad qué nos van a ayudar ustedes para apalear al diablo?", luego de la positiva respues-

39 Guevara Niebla, 1985, pp. 95-96.

40 Vaughan, 2001, p. 337.

41 "La escuela socialista responde a los deseos del proletariado. Interesantes declaraciones del C. Secretario de Educación Pública. Lic. Gonzalo Vázquez Vela”, El Maestro Rural, 4, 1935, portada.

42 He desarrollado estas ideas en Sosenski, 2010.

43 Guevara Niebla, 1985, p. 96.

44 List Arzubide, 1997, p. 29. 
ta que seguramente recibían de los entusiastas espectadores, Comino comentaba al Negrito: "¿ya ves? Somos muchos contra él solo”. ${ }^{45}$

La liberación y transformación revolucionaria de la sociedad, así como un discurso impregnado de materialismo histórico, pretendieron trascender la representación e instalarse en las emocionadas mentes infantiles que presenciaban el espectáculo teatral. El cooperativismo, el unionismo y la solidaridad para enfrentar la explotación se difundieron en varias obras del teatro guiñol. En La invernada de los animales, adaptación de Graciela Amador de la fábula del escritor ruso Alekandr Nikoalevich Afanasiev, se exaltaba la cooperación para la armonía de la colectividad. Si la escuela socialista era corporativista porque creaba "en el niño un amplio sentido de solidaridad y asociación en el esfuerzo", lo educaba "para la producción colectivizada" y le proporcionaba "las posibilidades de disfrutar íntegramente los beneficios de la vida social", ${ }^{46}$ los títeres cumplían su función didáctica y mostraban que las injusticias debían de ser enfrentadas en conjunto.

El discurso reiterativo del valor del trabajo retomaba concepciones decimonónicas al presentarse con su antítesis: el ocio. La pereza era perjudicial y las obras infantiles se empeñaron en dejarlo muy claro. En el proyecto de creación del "nuevo" hombre revolucionario "se atacaron costumbres y hábitos considerados negativos, contrarios en diversos sentidos a los objetivos y a las concepciones que se suponía debía tener el nuevo régimen" ${ }^{47}$ En Comino en el país de los holgazanes, el famoso personaje, aquí hijo de un zapatero, se declaraba enemigo del trabajo a pesar de la insistencia de sus padres que trataban de convencerlo de que "en el universo todo trabaja. Trabaja el Sol, alumbrando los campos y las ciudades. Trabaja el viento moviendo los molinos". ${ }^{48}$ El títere se negaba también a ir a la escuela, por ello era enviado "al país de los holgazanes", donde "nadie hace nada" para que aprendiera "lo que es no trabajar". En ese país, Comino encontraba un escenario apocalíptico. Nadie construye casas, no hay quien ordeñe a las vacas ni confeccione los vestidos. Tanta inutilidad provoca que algunas personas pierdan los brazos. Otras, la cabeza. El recurso del temor tiene éxito con Comino, quien asustado termina por convencerse. El títere toma el tren de regreso al país laborioso (se entiende que es México) y

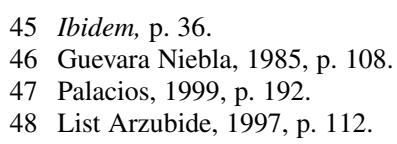


aprende la lección: "Papá, mamá, yo quiero trabajar y estudiar, tengo miedo de que se me caigan los brazos y las piernas, tengo miedo de andar sin cabeza". ${ }^{49}$ Perder la cabeza por la holgazanería es un recurso que el escritor List Arzubide repite en su obra Comino pierde la cabeza. Ahí, ante la negativa de Comino de trabajar en su hogar y en la escuela, su maestra le cuenta la siniestra historia de aquel país en el que los holgazanes pierden los brazos y la cabeza. Con este duro mensaje, además de la idea del trabajo como virtud, la obra también pretendía fomentar en el niño el espíritu de disciplina.

El mismo mensaje fue repetido en Comino ama el trabajo, considerada por la Comisión de repertorio como una obra de verdadera diversión para los niños pero, sobre todo, una obra que "fomenta el amor al trabajo, modificando el viejo concepto de que la labor es un castigo"..$^{50}$ Lo mismo sucedió con Zimbalú o el gorila perezoso, en donde los personajes, todos animales - la fábula era un recurso muy utilizado por el teatro guiñol—, ${ }^{51}$ demostraban "que todo aquel que se aprovecha del trabajo de los demás merece un castigo", aquí se agregaba "que debe darse oportunidad a estos individuos a fin de que corrijan sus defectos". ${ }^{52}$ A esta se la consideró como "una obra digna de representarse por la clara tendencia social que la anima y por sus grandes posibilidades de diversión para los niños". Concentraba la idea social de la cooperación y de "que todo el mundo debe trabajar para comer y nadie vivir del trabajo de los demás". ${ }^{53}$

Las autoridades insistían en que la escuela debía "convertir el trabajo no sólo en el centro de instrucción" sino "crear en los alumnos la conciencia de trabajo como medio, el más eficaz y el verdaderamente efectivo, para fomentar las relaciones humanas. Igualmente, inculcar la convicción de que el trabajo ocupa el primer lugar en el desarrollo de las sociedades". ${ }^{44}$ Las actividades económicas de los niños eran una condición de existencia de la infancia pobre mexicana de la posrevolución, existía un importante número

49 Ibidem, p. 120.

50 AHSEP, Bellas Artes, Teatro, 73, 11, "Carta al jefe del departamento", México, 12 de marzo de 1934, f. 53.

51 Muchas de las obras conservaban la estructura de la fábula, historias breves, con moraleja y con uso de animales o alegorías de seres humanos y de sus relaciones en la sociedad, para captar la atención de los niños.

52 AHSEP, Bellas Artes, Teatro, 73, 27, "Carta al jefe de departamento", México, 14 de mayo de 1934 , f. 81.

53 Ibidem, 73, 11, "Carta al jefe del departamento", México, 12 de marzo de 1934, f. 53.

54 “Trabajos manuales”, El Maestro Rural, 9, México, 1936, p. 22. 
de niños laborando en las calles, fábricas y talleres. Con la pedagogía de la acción y la escuela socialista miles de niños escolarizados participaron cotidianamente como aprendices de oficio en los talleres escolares. ${ }^{55}$ Sin embargo, fue la escuela socialista la que se preocupó por la formación de una conciencia de clase entre la niñez. Comino va a la huelga expuso los beneficios del paro laboral. Comino instó a sus compañeros a declarar la huelga convencido por un herrero de su calle que le explicó "que sólo ocho horas de trabajo es lo que debe tener todo obrero" ${ }^{56} \mathrm{Al}$ declarar la huelga, el pequeño Comino señalaba: "ya no trabajaremos, hasta que se admitan nuestras condiciones" ${ }^{57}$ En esta obra los títeres mostraron al público infantil que la unión hacía la fuerza, pero también que la huelga era un valioso recurso para la defensa del obrero: "hemos triunfado [...] ya saben muchachos, si los quieren hacer trabajar más de las ocho horas y no les pagan los domingos tiempo doble, a la huelga y duro contra el patrón". La representación terminaba cuando los títeres apaleaban al explotador, que salía chillando mientras todos vitoreaban " $i v i v a$ la huelga!". ${ }^{58}$

Las obras de teatro infantil mostraban no sólo las realidades de las actividades económicas de un sector de la niñez mexicana sino también el maltrato, la explotación y las injusticias que sufrían los pequeños aprendices. En Periquillo y el Usurero, escrita por de Graciela Amador, el pequeño Periquillo, colocado como aprendiz de un usurero, sufría los malos tratos y la explotación de su patrón Don Ferruco, quien se negaba a pagarle (“¡en dónde se ha visto que le paguen a uno por enseñarle!”). Periquillo sufría las desventajas del trabajo infantil hasta que decidía rebelarse y asustar al viejo Ferruco, logrando que huyera dejando en la mesa la paga del sueldo del niño y las escrituras de sus deudores..$^{59}$

Si la antítesis del trabajo era la holgazanería, su binomio era la escuela, ahí los niños trabajaban estudiando o aprendiendo oficios. El personaje de La Luna en una representación recitaba: "Para que mañana/ con la luz del día/escuela y trabajo/ os den alegría" ${ }^{60}$ Ambas actividades se consideraban benéficas para la infancia. ${ }^{61}$ Comino se quejaba de que "ahora quieren que vaya a la escuela $[\ldots]$ y eso es mucho trabajo. Mejor déjenme sin

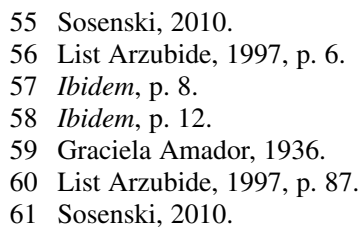


comer pero no voy a la escuela". ${ }^{62}$ La Luna, en otra obra, señalaba: "pues niños, aquí o trabajan o no comen". ${ }^{3}$ Esta idea se repetía en varias obras de teatro guiñol. En La Rana y el Buey, de Graciela Amador, una ranita explotada exigía poéticamente el fin de los abusos de la Rana Burguesa: "ahora no están los tiempos / como usted se lo supone / se acabaron los abusos: / ¿Quien no trabaja no come!". ${ }^{64}$ No deja de sorprender que la vieja frase de San Pablo, y que luego acuñó la ideología socialista de "el que no trabaja no come", fuera también la que tapizara una de las paredes del comedor de la Escuela Industrial Francisco I. Madero, a la que asistían niños pobres del barrio de La Bolsa desde 1921.

Los niños debían contribuir a la economía familiar si estaban en casa, o a la nacional si estaban en instituciones estatales. El mismo tenor seguía la obra El Gigante, de Elena Huerta, en la cual un niño de un grupo de amigos de un barrio pobre se comía el almuerzo de los demás convirtiéndose en un gigante autoritario, furioso y holgazán. ${ }^{65} \mathrm{~A}$ cambio de no devorarlos uno por uno el gigante exigía alimento a los demás. Los amigos conseguían viandas para ese gigante gracias a su trabajo, pero cansados, y advirtiendo la injusticia, se unían para cavar un pozo en el que caía el furibundo barrigón. La obra terminaba con la exclamación de Comino: "el que no trabaje que no coma" y el grito de Pepito: "Unidos vencimos al gigante ladrón". Con estos discursos las representaciones llamaban al cooperativismo, al unionismo y a la conciencia de clase para afrontar las injusticias de manera colectiva, no es fortuito que se presentaran en el contexto de la creación de las grandes centrales obreras y campesinas que inauguró el régimen cardenista.

La explotación y la desigualdad eran los flagelos del capitalismo. El trabajo servía para construir una sociedad "feliz", en la que no existiera la explotación. En Comino vendedor ambulante se exhibía "fustigándolo, el tipo del individuo que se aprovecha del trabajo de los niños en beneficio propio, haciendo que los pequeños se defiendan de los explotadores". ${ }^{66} \mathrm{Al}$ final de la obra La rana y el buey todas las ranitas exclamaban: "isomos libres y felices, viviremos trabajando!".

62 List Arzubide, 1997, p. 113.

63 Ibidem, p. 55.

64 Espinoza, 1988, p. 38.

65 Giménez Cacho, 2008, p. 13.

66 AHSEP, Bellas Artes, Teatro, 73, 27, "Carta al subjefe del Departamento de Bellas Artes", 14 de mayo de 1934, f. 83. 
Como hemos señalado, había muchas obras sin mensaje ideológico explícito. La comedia cómica Firuleque en el circo, de Germán Cueto, presentaba sólo una ligera enseñanza ética que mostraba que el esfuerzo para vencer las dificultades y conseguir lo que se desea únicamente podía hacerse a través del trabajo, que había actividades que parecían fáciles pero no lo eran y que la mejor opción para los niños era la escuela. ${ }^{67}$

\section{Los títeres y la higiene}

En México, a principios del siglo XX, los encargados de la salud pública enfatizaron en que mejorando la higiene popular se podría estimular la salud económica nacional y el trabajo de hombres y mujeres.$^{68}$ Como señala Ernesto Aréchiga, "la salud era un asunto trascendental, no sólo a nivel individual sino en sentido económico y social a la vez" ${ }^{69}$ La higiene requería que el individuo se sometiera a una disciplina por el bien de la colectividad y acatara las prescripciones sanitarias recomendadas por el Gobierno. La Constitución de 1917 había dotado "al Estado de una capacidad legal de acción que no había tenido nunca antes en relación con la salubridad pública" y esto hizo que el Estado emprendiera "campañas — de vacunación, de erradicación de plagas, de higienización urbana y rural-". ${ }^{70}$

Entre 1920 y 1940, la SEP se enfocó a la divulgación de los principios higiénicos, promovió la difusión de la utilización de vacunas, la importancia de hervir el agua o del baño diario, con ello pretendía que tanto los sectores urbanos como los rurales cambiaran sus hábitos y costumbres tradicionales por los que se consideraban saludables y modernos. ${ }^{71}$ "Fue tal la importancia que se le dio a la denominada 'educación higiénica' que tanto el Departamento de Salubridad como la Secretaría de Educación Pública crearon áreas especializadas en educación y propaganda en materia de higiene cuyas funciones se entreveraban con relativa facilidad". ${ }^{2}$

Hubo varios medios y vehículos a través de los cuales el régimen promovió sus políticas, doctrinas y opiniones "para informar al público y al

67 Espinoza, 1988, pp. 49-54.

68 Bliss, 2006, p. 198.

69 Aréchiga, 2007, p. 61.

70 Ibidem, pp. $66-67$.

71 Gudiño, 2008, p. 71.

72 Aréchiga, 2007, p. 73. 
mismo tiempo modificar los comportamientos". ${ }^{73}$ Se usaron publicaciones oficiales como El Sembrador o El Maestro Rural, centenares de carteles, obras de teatro, libros de texto, folletos, "revistas, periódicos, presentaciones de conferencias, exhibiciones cinematográficas y transmisión de programas radiofónicos". ${ }^{74} \mathrm{~A}$ estos medios se sumaron las obras de teatro guiñol, que complementaban el trabajo de los visitadores sanitarios a los hogares, las campañas de vacunación y la propaganda. Eran parte de un amplio programa de educación higiénica que trataba de convertir a las escuelas en centros de activismo pro-salud.

Para las autoridades era claro que los hábitos higiénicos se formaban esencialmente en dos espacios: el hogar y la escuela. Esta última se consideraba un espacio privilegiado "que permitiría la incorporación de la población campesina al proyecto nacional, dado que gracias a la instrucción que recibirían por parte de los maestros rurales, paulatinamente sería posible que numerosas comunidades salieran del atraso y se tornaran en agentes activos y productivos de la sociedad". ${ }^{75}$

Esta fue una época en la que se dio una "empresa de higienización colectiva de la sociedad" que requería "el consentimiento y el apoyo de la población; emprender una ardua y eficaz labor de persuasión, de convencimiento y de instrucción". ${ }^{76}$ El Departamento de Salubridad Pública señalaba el grado de responsabilidad concéntrico que tenía el individuo en el devenir de la nación: "conservar la salud es responsabilidad que uno tiene consigo mismo, con la familia, con el país y con la raza". ${ }^{77}$

Las obras de guiñol reprodujeron de una u otra manera los principios que se habían publicado en el Código de moralidad de los niños que concurren a las escuelas primarias, de 1925: tener buena alimentación, hacer ejercicio, dormir lo suficiente, conservar limpios el vestido, el cuerpo y el espíritu, proteger la salud de los demás, desarrollarse con fuerza y agilidad. ${ }^{78} \mathrm{Y}$ coincidían también con los "Doce mandamientos de la higiene" publicados en El Maestro Rural, que recomendaban dejar las ventanas abiertas en la noche para que entrara aire fresco en la casa, no escupir en el suelo de los lugares públicos ("ya que de esta manera puede usted incons-

73 Ibidem, p. 72.

74 Gudiño, 2008, p. 72; Aréchiga, 2007, p. 70.

75 Gudiño, 2008, pp. 73, 76-77.

76 Agostoni, 2008, pp. 287, 308.

77 Bliss, 2006, p. 196.

78 Aréchiga, 2007, p. 80. 
cientemente arrojar gérmenes de enfermedades peligrosas"), limpiar el polvo del hogar ("donde hay polvo hay microbios"), no dejar ollas a la intemperie en la cocina pues entrarían en ellas "la sucia mosca, las cucarachas y otras sabandijas", cuidar los barriles de agua, comprar pan y leche en lugares aseados, sacar la basura de la casa, evitar juntar agua en cortezas de coco o botellas, hervir la leche y el agua. ${ }^{79}$

La obra Firuleque de vacaciones demostró las ventajas de la vida del campo en la salud y atacó los sistemas tradicionales de curación en enfermedades que requerían solamente higiene. Hay que recordar que una de las ideas centrales del proyecto guiñol eran cambiar la educación del viejo régimen por una nueva, que promoviera los espacios al aire libre y los hábitos de limpieza en el hogar. La Comisión de repertorio señaló que la obra estaba proyectada más bien para educar a las madres y no tanto a los niños y que era necesario "establecer un contraste entre la vida malsana de la ciudad y la del campo". ${ }^{80}$ La urbanización en alza aparecía como uno de los principales enemigos de la salud.

Así como los regímenes posrevolucionarios establecieron una guerra materialista contra los enemigos de la Revolución, patrones explotadores o empresarios abusivos, también lo hicieron contra los microbios que diseminaban enfermedades entre la población mexicana. Esas ideas se tradujeron al lenguaje infantil en las pláticas de Comino. En Lávate la boca, Comino, de Germán List Arzubide, un pequeño ejército compuesto por el Cepillo de dientes, la Pasta dentífrica y el Dentista, desarrolló una enconada ofensiva contra los microbios de la Piorrea, la Fiebre Tifoidea y la Diarrea, que amenazaban arrancar los dientes a Comino y matarlo de enterocolitis o fiebre tifoidea. El campo en el que se libraba esta batalla era la boca del títere, quien había acudido al dentista por un fuerte dolor de muelas a consecuencia de no lavarse los dientes. El tono didáctico se enfatizaba a través de coros y bailables ejecutados por los personajes de cada bando y amenizados con la música que tocaba el fonógrafo. Los microbios cantaban:

\author{
Somos los microbios \\ que en todas las edades \\ damos a las gentes \\ mil enfermedades.
}

79 "Los doce mandamientos de la higiene", El Maestro Rural, 12, 1935, p. 27.

80 AHSEP, Bellas Artes, Teatro, 73, 11, "Carta al jefe del Departamento de Bellas Artes", 12 de marzo de 1934, f. 53. 


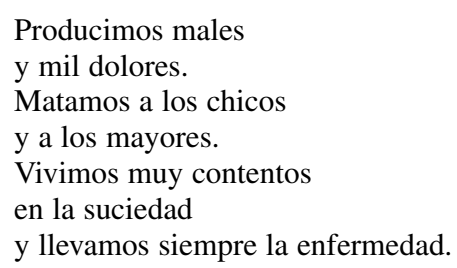

El Cepillo y la Pasta respondían:

$$
\begin{aligned}
& \text { Mi amiga la pasta } \\
& \text { y yo el cepillo } \\
& \text { damos a los dientes } \\
& \text { la salud y el brillo. } \\
& \text { La alegría traemos } \\
& \text { siempre de regalo; } \\
& \text { para los microbios } \\
& \text { traemos un palo. } \\
& \text { Lávate los dientes } \\
& \text { de noche y de día. } \\
& \text { que pasta y cepillo } \\
& \text { te dan alegría. }
\end{aligned}
$$

En otra obra titulada Comino desaseado, el pequeño títere aparecía en el escenario sucio y lleno de parásitos. Según las educadoras de los jardines de niños esa imagen servía para despertar en la infancia "hábitos de aseo". Un personaje, El Piojo, atemorizaba a los pequeños y les producía "miedo por sus dimensiones y ahora nadie quiere tener éstos animales que en este lugar eran muy comunes." Las representaciones tenían como objetivo impresionar "la imaginación de los niños asistentes" por lo que, tanto el vestuario de los personajes como el escenario, se diseñaban con ese propósito. Un pálido Comino sin ganas de jugar, comer o estudiar rompía con el paradigma de niños de mejillas sonrosadas y "siempre contentos" que difundían los concursos de belleza infantil en la prensa del periodo ${ }^{82}$ En un jardín de niños de Iztapalapa los alumnos habían escuchado esta obra con sumo interés respondiendo bulliciosamente a las preguntas que les hacían los títeres. ${ }^{83}$ En ese texto el diagnóstico médico fue que a Comino se le había "empobrecido la sangre" por falta de ejercicio, levantarse tarde y dor-

81 List Arzubide, 1997, pp. 144, 147.

82 Ibidem, p. 96.

83 AHSEP, Bellas Artes, Teatro, 71, 33/34, "Carta al jefe del departamento de Bellas Artes", 30 de enero de 1934, f. 42. 
mir con la ventana del cuarto cerrada. El tratamiento necesario eran sol, agua y aire. Estos darían a Comino higiene, salud, fuerza, alegría, frescura, renovación sanguínea, luz y vida:

\footnotetext{
Yo soy el Sol, yo soy el agua, yo soy el aire.

Andamos juntos alegremente por todas partes.

Toma mi luz, baña tu cuerpo, llena tu pecho.

Serás un niño, sano, limpio, siempre contento.

A todo el mundo cuando nos llama damos salud.

Ven con nosotros y esa dicha la tendrás tú. ${ }^{84}$
}

La obra concluía con la felicidad de Comino, que aparecía ya no pálido sino ruborizado, cantando la moraleja: "con mis tres amigos, me siento feliz. Tengo mucha hambre y muchos deseos de estudiar, de ayudarte en tus trabajos. A ellos les debo mi alegría". ${ }^{5}$

En Perico el desaseado, el niño Perico, a quien horrorizaba el agua fría, recibía los regaños de su tía que le decía: "es vergonzoso tu desaseo". Impedido de entrar a clase por su suciedad, era enviado al peluquero, a quien le era imposible cortarle el pelo, endurecido ya como las ramas de un árbol. Sólo un leñador lograba hacer el corte de la melena que albergaba todo tipo de animales. Después de ese tratamiento, Perico recordaba las lecciones de sumas y regresaba a la escuela. El niño revolucionario debía de ser higiénico, la suciedad se vinculaba con un mundo animal, casi "primitivo" y contrario a la tan ansiada civilización, por ello los niños, como rezaba esta obra, no debían tener "la melena alborotada" y "mugrosa", las uñas largas y negras "como las de un león", la cara sucia, o saltar de rama en rama "como un orangután". La limpieza, la alfabetización, las matemáticas (un perro del circo le gana a Comino en una multiplicación) diferenciaban a los seres humanos de los animales. Esta era la lección que dejaba Comino y los animales.

Otras obras aludieron a una de las enfermedades sociales más temidas del periodo: el alcoholismo, que era visto "como una de las causas más serias del deterioro físico, mental y moral de los campesinos, lo cual además se traducía en bajo rendimiento y nula productividad". ${ }^{86}$ Junto con la sífilis y la tuberculosis, el alcoholismo preocupaba a los reformadores higienistas revolucionarios porque incapacitaba a los adultos en sus edades

84 List Arzubide, 1997, p. 102.

85 Ibidem, p. 106.

86 Gudiño, 2008, p. 82. 
más productivas, ponía en peligro la salud y amenazaba la productividad de los niños mexicanos, ciudadanos y trabajadores del futuro ${ }^{87}$ Pedro Muro, funcionario de la SEP, señalaba que el alcohol era "un traidor a la Revolución, un elemento de regresión, porque el borracho no puede trabajar". ${ }^{88}$ Así, en la obra Comino combate al vicio, el personaje lidiaba exitosamente con el alcoholismo de su padre obrero. ${ }^{89}$

Las ideas que promovían los títeres formaban parte de un corpus discursivo oficial que insistía en el aseo, los hábitos de higiene o la ventilación de las habitaciones. Sin embargo, como señala María Rosa Gudiño, "la vida material de los campesinos era una seria limitante para la puesta en práctica de las recomendaciones higiénicas", pronto se hizo "tangible y visible una realidad económica y social incompatible con la higiene. Es decir, la falta de saneamiento en numerosas comunidades no era sólo un problema cultural" sino de extrema pobreza. ${ }^{90}$ Los proyectos gubernamentales carecieron de las condiciones idóneas que permitieran poner en práctica la teoría entre la población rural y urbana. Existía un "enorme abismo entre las acciones, los programas y las campañas de salubridad e higiene y la realidad social y económica de las poblaciones campesinas". ${ }^{91}$

\section{Reflexiones finales}

Es importante cuestionar si este proyecto cumplió con los objetivos esperados, ¿fue exitoso?, ¿los niños comprendieron la importancia social del trabajo y de la higiene?, ¿hasta dónde se convirtieron en portavoces del discurso oficial como pretendían las autoridades? Elena Jackson se ha encargado minuciosamente de analizar los problemas asociados con la recepción infantil a estas producciones culturales de la posrevolución y plantea que los pequeños espectadores no captaron del todo la ideología revolucionaria que promovían los títeres pues "en muchos casos, debido a diferencias culturales o la falta de madurez de parte de los niños más jóvenes, los oficiales tuvieron que alterar el contenido de los espectáculos porque los niños mostraron evidencia en sus dibujos que no siempre entendí-

\footnotetext{
87 Bliss, 2006, p. 197.

88 Ibidem, p. 199.

89 Ibidem, p. 197.

90 Gudiño, 2008, p. 81.

91 Ibidem, pp. 94-95.
} 
an lo que tenían que aprender, y no siempre veían lo que tenían que ver en los títeres". ${ }^{92}$ Los maestros enviaban cartas a la SEP en las que señalaban que los niños "se espantaban con los títeres, creyendo que eran seres vivos o monstruos". Para muchos eran seres reales y después de la función quedaban muy asustados. A veces las educadoras debían "llevarlos a ver a los manipuladores mientras trabajaban" pero aún así no querían presenciar la continuación de la función. ${ }^{93}$ Algunos niños explicaban a sus compañeros que los muñecos se movían “¡Por electricidad!”. ${ }^{44}$ Jackson sugiere que "los niños más chiquitos no pudieron recibir con mayor claridad los mensajes de los títeres porque estaban obsesionados con su presencia física", ${ }^{95} \mathrm{de}$ tal forma eran los niños más grandes quienes advertían que los títeres eran una representación.

Los docentes atestiguaban que las presentaciones habían sido "muy aplaudidas", que había reinado "un verdadero placer y alegría entre alumnos y campesinos", quienes prodigaban "nutridos aplausos". Es cierto que probablemente muy pocos se hubieran sentido libres para expresar opiniones críticas al proyecto de teatro guiñol, y que muchos participaran de la retórica oficial y la difundieran, pero la titiritera Lola Cueto relataba que detrás del telón veía "por un agujerito los ojos negros de los niños [...] pendientes, pendientes, intrigados por no saber qué es lo que pasa, si de veras hablan los muñecos, quién los mueve". ${ }^{96}$

Angelina Beloff, que elaboraba los muñecos guiñol, estaba convencida de que "la imagen viviente del muñeco se imprime con fuerza en la mente del niño y todo lo que este muñeco hace y dice, es para él una verdad y un ejemplo". ${ }^{97}$ Juan Bustillo Oro señalaba que la obra Comino vence al dia$b l o$, para los niños, no era más que "una alegre historieta en que dos niños valientes apalean al que se disfraza de demonio para lograr que lo sirvan y obedezcan por medio del terror", pero destacaba que "el oculto propósito moral" de esta obra se infiltraba en las mentes infantiles en "el momento mismo en que cae el telón para preocuparlos después durante muchos días". ${ }^{98}$ Al parecer, después de varias semanas, los niños seguían expresan-

92 Jackson, 2008.

93 AHSEP, Bellas Artes, Teatro, 71, 33/34,"Carta al jefe del departamento de Bellas Artes", México, 7 de marzo de 1934, f. 79.

94 Gaitán Rojo, 2009, p. 64.

95 Jackson, 2008.

96 Gaitán Rojo, 2009, p. 64.

97 Beloff, 1945, pp. 168, 188.

98 Bustillo Oro, 1938, p. 37. 
do "con toda clase de detalles en su lenguaje sencillo" lo que habían visto en el escenario "sin olvidar nada". .9

Los niños arrojaban confeti a los muñecos, aplaudían al ritmo de la música y tomaban parte en los diálogos. Sin embargo faltan más investigaciones que señalen si esta producción cultural, junto con muchas otras, hicieron realmente que la generación de niños de la década de 1930 consolidara una ideología que considerara al trabajo, al unionismo, la huelga, la salud y la higiene como los pilares de la sociedad mexicana.

Es probable que los mexicanos adoptaran selectivamente la información higiénica como ellos creían que les podía ser útil en sus propias vidas y que conservaran sus ideas acerca de la higiene personal y el bienestar individual en formas que se enfrentaban abiertamente a las visiones de los reformadores de cómo mejorar la salud de la nación. ${ }^{100}$ Es posible también que esas políticas y su retórica no hayan tenido el éxito deseado, es decir, que los hábitos, costumbres y prácticas divergieran de los discursos y teorías materialistas históricas o higiénicas. Quizá los "grupos populares fueran adoptando un lenguaje propio de la educación y la propaganda en materia de higiene, haciendo uso de esos argumentos para intentar favorecer sus propios intereses". ${ }^{101}$ También pudo haber sucedido que existiera "una frontera muy tenue entre la persuasión y la coerción en las campañas de salud pública, despertando a menudo la desconfianza y la resistencia de la ciudadanía". ${ }^{102}$

Hacen falta muchos otros estudios para advertir si el mensaje del trabajo y la higiene como redentores sociales fue captado por los niños y si estos marcaron su vida adulta, pero es indudable que fueron grabados por los muñecos guiñol. "El impacto visual del teatro guiñol en los niños es, pues, un recuerdo que se guarda en la memoria; forma parte de la historia personal", destacó una mujer que durante su infancia había asistido a las funciones. ${ }^{103}$ Los niños extrañaban a Comino, a Firuleque y a Periquillo cuando estos tomaban el autobús de regreso y se alejaban de las poblaciones. Al "Querido Cominito" le escribían cartas en las que le decían: "pronto te esperamos para aplaudirte mucho", "deseamos que vuelvas pronto y que

99 AHSEP, Bellas Artes, Teatro, 71, 33-34, "Se da a conocer las impresiones observadas en los niños durante una representación de teatro infantil”, México, 27 de febrero de 1934, f. 71.

100 Bliss, 2006, p. 213.

101 Aréchiga, 2007, pp. 87-88.

102 Ibidem, p. 67.

103 Gaitán Rojo, 2009, p. 146. 
nos contestes las cartas", "ya te queremos ver. Hace mucho que no vienes, ¿qué no nos quieres? Nosotros sí te queremos, mucho". ${ }^{104}$ Los niños también le dedicaron poemas. "Durante una de sus giras por minúsculos pueblos semi-ignorados del Estado de Tamaulipas, el Grupo Comino fue objeto del homenaje de los jóvenes poetas campesinos — de 9 a 13 años—, quienes dedicaron al popularísimo muñeco versos de una frescura y de una imaginación invaluable". ${ }^{105}$

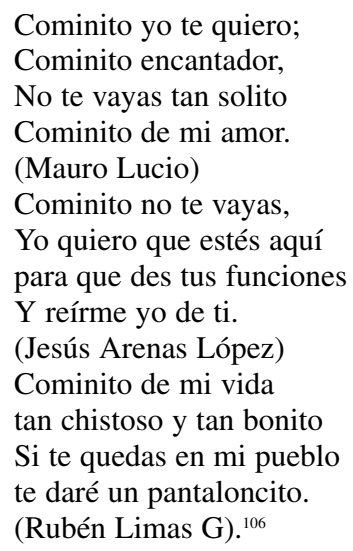

Con el ocaso del cardenismo, en febrero de 1940, en el vestíbulo del Palacio de Bellas Artes, ubicado en el centro de la capital, fueron exhibidos ciento sesenta muñecos guiñol, los esbozos que habían sido elaborados para construirlos, fotos, recortes y recuerdos de los ocho años de vida de los grupos Comino, Periquillo y El Nahual. Hasta ese entonces estas compañías habían celebrado cerca de ocho mil representaciones. ${ }^{107} \mathrm{~A}$ mediados de los años cuarenta los grupos comenzaron a disgregarse, con excepción de El Nahual, de Lola Cueto, que continuó sus funciones hasta finales de la década de 1970. El fin del cardenismo y su "desradicalización" a partir de $1938^{108}$ fue marcando cambios y contradicciones en la postura ideológica de los titiriteros, del gobierno y las autoridades de la SEP, situación que sumada a la escasez de recursos económicos y la maquinaria burocrática,

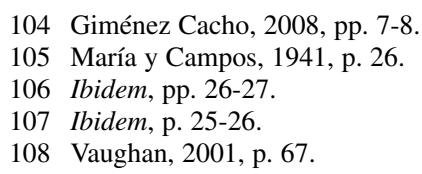


terminaron con este proyecto y con muchos otros, como las misiones culturales, las concesiones a grupos conservadores o a movimientos magisteriales radicales. No es fortuito que para 1947 el subdirector del Departamento de Bellas Artes, Julio Prieto, decidiera cancelar las actividades de los titiriteros acusándolos de actuar de manera anárquica y antagónica por no sumarse a las ideas de los nuevos gobiernos en turno. ${ }^{109}$ Es importante destacar que mientras el teatro guiñol sostenido por el Departamento de Bellas Artes fue apagando sus luces, aparecían otros proyectos como el de Gilberto Ramírez Alvarado con Don Ferruco, sostenido por el Departamento de Acción Social del Departamento del Distrito Federal o, pocos años después, en 1954, el del "teatro Petul" en Chiapas, como una iniciativa del Instituto Nacional Indigenista para difundir preceptos higiénicos, escolares y castellanizantes entre la población campesina del país. ${ }^{110}$

El teatro guiñol cardenista formó parte de un amplio proyecto estatal que buscaba formar ciudadanía social, impregnar a los mexicanos de una ideología socialista y, a través de un didactismo político, transformar las prácticas individuales, las actitudes y las conductas. El teatro infantil, patrocinado por el Estado y sus artífices, se convirtió en legitimador de la obra posrevolucionaria y de las políticas culturales de higiene social y de propaganda del trabajo. Fue otro más de los intentos estatales para politizar la vida cotidiana, pública y privada y extender el poder del Estado a todos los niveles posibles.

Recibido el 8 de marzo de 2010 Aceptado el 2 de septiembre de 2010

\section{Bibliografía}

Claudia Agostoni: "Historia de un escándalo. Campañas y resistencia contra la difteria y la escarlatina en la ciudad de México", en Claudia Agostoni (coord.): Curar, sanar y educar. Enfermedad y sociedad en México, siglos XIX y XX, México, Universidad Nacional Autónoma de México, Benemérita Universidad Autónoma de Puebla, 2008, pp. 287-311.

109 Giménez Cacho, 2008, p. 13.

110 Lewis, 2008. 
NIÑOS LIMPIOS Y TRABAJADORES. EL TEATRO GUIÑOL POSREVOLUCIONARIO

Graciela Amador: Tres comedias para teatro infantil, México, Secretaría de Educación Pública, 1936.

Ernesto Aréchiga: "Educación, propaganda o 'dictadura sanitaria'. Estrategias discursivas de higiene y salubridad públicas en el México posrevolucionario, 1917-1945”, Estudios de Historia Moderna y Contemporánea de México, 33, México, 2007, pp. 57-88.

Angelina Beloff: Muñecos animados: historia, técnica y función educativa del teatro de muñecos en México y en el Mundo, México, Secretaría de Educación Pública, 1945.

Katherine E. Bliss: "For the Health of the Nation: Gender and the Cultural Politics of Social Hygiene in Revolutionary Mexico", en Mary Kay Vaughan y Stephen E. Lewis (eds.): The Eagle and the Virgin. Nation and Cultural Revolution in Mexico, 1920-1940, Durham, Duke University Press, 2006, pp. 196-218.

Juan Bustillo Oro: "La moral en el Teatro infantil", El Maestro Rural, 11 y 12, México, 1938, p. 37.

Tomás Espinoza: Galería de teatro para niños, México, Coordinación General de Prestaciones Sociales/Coordinación de Promoción Cultural, Secretaría General/Unidad de Publicaciones y Documentación, Instituto Mexicano del Seguro Social, 1988.

Carmen Gaitán Rojo (coord.): Lola Cueto. Trascendencia mágica, 1897-1978, México, Instituto Nacional de Bellas Artes, 2009.

Marisa Giménez Cacho (coord.): Época de Oro del Teatro Guiñol de Bellas Artes, 1932-1965, México, Consejo Nacional para la Cultura y las Artes, 2008.

María Rosa Gudiño C: "Educación higiénica y consejos de salud para campesinos en El Sembrador y El Maestro Rural, 1929-1934", en Claudia Agostoni (coord.): Curar, sanar y educar. Enfermedad y sociedad en México, siglos XIX y XX, México, Universidad Nacional Autónoma de México, Benemérita Universidad Autónoma de Puebla, 2008, pp.71-97.

Gilberto Guevara Niebla: La educación socialista en México (1934/1945), México, El Caballito, SEP Cultura, 1985.

Fernando Horcasitas: Teatro náhuatl. Épocas novohispana y moderna, México, Universidad Nacional Autónoma de México, 2004, Tomo 1.

Lynn Hunt: Politics, Culture and Class in the French Revolution, Berkeley, University of California Press, 1984.

Elena Jackson: "Comino Vence al Diablo and other Terrifyng Episodes: Teatro Guiñol's Itinerant Puppet Theater in Mexico, 1930-1940”, The Americas, A Quarterly Review of Inter American Cultural history, 27, 2011 (en prensa).

Elena Jackson: "Hacia una historia cultural de la niñez: cartas, dibujos y otros documentos producidos por los niños", ponencia presentada en el IX Encuentro de Historia de la Educación, Xalapa, Veracruz, 26-28 de noviembre 2008 . 
Lisa Kirschenbaum: Small comrades. Revolutionizing Childhood in Soviet Russia, 1917-1932, New York, Routledge Falmer, 2001.

Alan Knight: "Popular Culture and the Revolutionary State in Mexico", Hispanic American Historical Review, 74-3, Washington, 1994, pp. 393-444.

Stephen E. Lewis: "Mexico's National Indigenist Institute and the Negotiation of Applied Anthropology in Highland Chiapas, 1951-1954”, Ethnohistory, University Park, 55-4, 2008, pp. 609-632.

Germán List Arzubide: Teatro guiñol, México, Universidad Nacional Autónoma de México, 1997.

Armando María y Campos: Teatro mexicano de muñecos. 25 piezas de teatro guiñol, México, El Nacional, 1941.

Alejandro Ortiz: Teatro y vanguardia en el México posrevolucionario (19201940), México, Universidad Autónoma Metropolitana, 2005.

Guillermo Palacios: La pluma y el arado. Los intelectuales pedagogos y la construcción sociocultural del "problema campesino" en México, 1932-1934, México, El Colegio de México, 1999.

Susana Sosenski: Niños en acción. El trabajo infantil en la ciudad de México, 1920-1934, México, El Colegio de México, 2010.

Beatriz Urías Horcasitas: "El 'hombre nuevo' de la posrevolución”, Revista Letras Libres, 101, México, 2007, pp. 58-61.

Mary Kay Vaughan: La política cultural en la Revolución. Maestros, campesinos y escuelas en México, 1930-1940, México, Fondo de Cultura Económica, 2001.

James W. Wilkie y Edna Monzón Wilkie: Frente a la Revolución Mexicana. 17 protagonistas de la etapa constructiva. Entrevistas de historia oral, México, Universidad Autónoma Metropolitana, 2001. 